\title{
One-Pot, Surfactant-Free Synthesis of Gold Nanostars and Evaluation of Their Antibacterial Effects against Propionibacterium acnes
}

\author{
Phat Trong Huynh $\mathbb{D},,^{1,2}$ Giang Dang Nguyen $\mathbb{D}^{1},{ }^{1}$ Khanh Thi Le Tran $\mathbb{D}^{1},{ }^{1}$ Thu Minh Ho $\mathbb{D},{ }^{1}$ \\ Bich Thi Duong, ${ }^{3}$ Vinh Quang Lam, ${ }^{2,4}$ and Thanh Vo Ke Ngo ${ }^{1}$ \\ ${ }^{1}$ Research Laboratories of Saigon Hi-Tech Park, 700000, Vietnam \\ ${ }^{2}$ University of Science, VNU-HCM, 700000, Vietnam \\ ${ }^{3}$ Tay Do University, 94000, Vietnam \\ ${ }^{4}$ Vietnam National University-HCMC, 700000, Vietnam
}

Correspondence should be addressed to Phat Trong Huynh; phat.huynhtrong@shtplabs.org and Thanh Vo Ke Ngo; thanh.ngovoke@shtplabs.org

Received 10 November 2020; Revised 14 February 2021; Accepted 26 February 2021; Published 10 March 2021

Academic Editor: Raul Arenal

Copyright (c) 2021 Phat Trong Huynh et al. This is an open access article distributed under the Creative Commons Attribution License, which permits unrestricted use, distribution, and reproduction in any medium, provided the original work is properly cited.

\begin{abstract}
Anisotropic gold nanoparticles, especially gold nanostars, are used in many fields of biomedical applications such as sensing, targeted drug delivery, and diagnostic and photothermal therapy. In this study, we introduced a novel application of gold nanostars as an antimicrobial agent. While spherical gold nanoparticles have an inappreciable effect, gold nanostars exhibit significant antibacterial activity. Besides, the seed-mediated method, a conventional technique for preparing gold nanostars, is rather complex and toxic to human and environment due to unsafe synthesized materials such as surfactants and reducers. In recent years, green chemistry for nanoparticle synthesis is attractive because of its advantages. Instead of the seed-mediated procedure, we present a facile and green procedure to synthesize gold nanostars using ascorbic acid as a reductant and chitosan as a directing-growth agent. The influences of reacting parameters were evaluated to determine the optimal conditions. Starshaped gold nanoparticles were successfully synthesized with average size tunning from $137.0 \pm 20.7 \mathrm{~nm}$ to $281.9 \pm 25.8 \mathrm{~nm}$ of the core and $14.0 \pm 4.4 \mathrm{~nm}$ to $54.2 \pm 11.9 \mathrm{~nm}$ of branches. Antibacterial activity against Propionibacterium acnes of gold nanostars was also investigated. Propionibacterium acnes is one of the main reasons causing acne vulgaris. The antibacterial test was evaluated by the plate count and well diffusion method. The results showed a significant effect that gold nanostars could be the prospective agent for replacing antibiotics in acne treatment.
\end{abstract}

\section{Introduction}

Acne vulgaris is one of the most popular chronic inflammatory dermatological problems affecting around $10 \%$ of the global population [1]. Moreover, it is also among top of three cutaneous diseases treated by dermatological doctors [2]. Therein, adolescence in the age $12-25$ years assumes $85 \%$ of cases affected by acne vulgaris, according to Global Burden of Disease (GBD) [3]. There are $85 \%$ of females reporting having acne while just $15 \%$ of males were affected [4]. The treatment for chronic inflammatory acne vulgaris requires a long period and patience. Lesions usually appear on skin including the back, shoulders, chest, and especially face, causing to take scars or bruises. This not only evokes the physical lesions but also impacts the quality of life [5]. The patients can have problems with depression, anxiety, social isolation, and low self-confidence [6]. There are many factors related to acne, but Propionibacterium acnes ( $P$. acnes) is believed to have an important role in the information or progression of acne vulgaris [7]. Propionibacterium acnes is a rod, anaerobic, Gram-positive bacterium [8]. Besides the association with the inflammatory skin, it is believed to play a role in 
TABLE 1: Latest studies on antibacterial activity of gold nanoparticles.

\begin{tabular}{|c|c|c|c|c|c|}
\hline Ref & Morphology & Functional agent & Type of microorganism & Average size $(\mathrm{nm})$ & Antibacterial effect \\
\hline \multirow{2}{*}[34]{} & \multirow{2}{*}{ Spheres } & \multirow{2}{*}{ Cryptolepis buchanani extract } & Staphylococcus aureus (+) & \multirow{2}{*}{$11.1 \pm 1.3$} & \multirow{2}{*}{ MIC $0.209 \mu \mathrm{g} / \mathrm{mL}$} \\
\hline & & & Acinetobacter baumannii (-) & & \\
\hline \multirow{2}{*}{ [35] } & \multirow{2}{*}{ Spheres } & \multirow{2}{*}{ Luteolin tetraphosphate } & Aeromonas hydrophila (-) & \multirow{2}{*}{9} & \multirow{2}{*}{ No activity } \\
\hline & & & Escherichia coli (-) & & \\
\hline \multirow{3}{*}[36]{} & \multirow{2}{*}{ Spheres } & \multirow{2}{*}{ Sophorolipid } & Staphylococcus aureus $(+)$ & \multirow{6}{*}{$40 \pm 10$} & \multirow{2}{*}{ MIC $25 \mu \mathrm{g} / \mathrm{mL}$} \\
\hline & & & Vibrio cholera (-) & & \\
\hline & \multirow{4}{*}{ Spheres } & \multirow{4}{*}{ Crinum latifolium } & Escherichia coli (-) & & \multirow{4}{*}{ No activity } \\
\hline \multirow{3}{*}[37]{} & & & Agrobacterium tumefaciens (-) & & \\
\hline & & & Bacillus subtilis (+) & & \\
\hline & & & Staphylococcus aureus (+) & & \\
\hline [38] & Spheres & Bovine serum albumin & Staphylococcus aureus $(+)$ & 5 & MIC $4.37 \mu \mathrm{g} / \mathrm{mL}$ \\
\hline$[39]$ & & & Escherichia coli (-) & & Agar diffusion method, \\
\hline [39] & Spheres & Platycodon grandiflorum plant extract & Bacillus subtilis (+) & 15 & $20 \mu \mathrm{g} / \mathrm{mL}$ \\
\hline
\end{tabular}

(+): Gram positive; (-): Gram negative.

other human infections and clinical conditions [9]. Treatment options for acne such as oral or topical use include benzoyl peroxide, salicylic acid, retinol, or antibiotics [10]. However, each option has disadvantages and side effects as follows: peeling, itching, erythema, and allergic reaction in the case of benzoyl peroxide [11]; retinoid irritation, dryness, erythema, purging, and stinging/burning in the case of using retinol [12]; and difficulty in breathing, dryness and peeling of skin, itching, welling of the eyes, face, lips, or tongue, and tightness in the throat in the case of using salicylic acid [13]. Antibiotics are common therapy for acne treatment; however, $P$. acnes become resistant to most antibiotics because of long-term use which led to failure in acne vulgaris treatment $[14,15]$.

Nanotechnology and nanomaterials are prospective methods for replacing conventional acne treatment $[16,17]$. Antimicrobial metallic nanoparticles such as noble- (copper, silver, and gold) [18-20], oxide- (zinc oxide, magnesium oxide, and tin oxide) [21-23], and carbon-based nanoparticles (carbon nanotube, graphene) [23, 24] were attractive and studied by researchers in several years. Among them, silver nanoparticles are one of the most common subjects due to great antibacterial activity [25]. However, there is dispute on the cytotoxicity of silver nanoparticles [26, 27]. By contrast, gold nanoparticles are high biocompatible and low toxic materials $[28,29]$. However, spherical gold nanoparticles have low or not significant antibacterial activity [30] (Table 1). Recently, some types of anisotropic gold nanoparticles, especially gold nanostars (GNS), were attractive because of their physical, chemical, and biological properties. The brief method for the preparation of gold nanostars is the seed-mediated method in the presence of a strong/mild reducing agent and anionic or cationic surfactants [31]. Sodium borohydride $\left(\mathrm{NaBH}_{4}\right)$ is used as a reducing agent while cetyltrimethylammonium bromide (CTAB), sodium dodecyl sulfate (SDS), and Triton X-100 are surfactants. Nevertheless, these materials are harmful to human and environment [31-33].
In recent years, green chemistry becomes a common trend in many fields of chemistry and materials [40] including nanomaterial synthesis [41]. This technology uses safe agents derived from nature for replacing toxic materials as well as applying low-cost and energy-efficient equipment [42]. Surfactant-free preparation of gold nanostars was first introduced by Yuan et al. [43]. In this report, we present a one-pot, surfactant-free synthesis of gold nanostars using chitosan. The role of chitosan (CS) is to direct growth, derived from crabs, shrimps, and other crustaceans. CS has many advantages of biological properties such as biocompatibility and antimicrobial and antifungal activity [44-46]. There are many biopolymers used to prepare metallic nanoparticles [47-50]; however, just spherical nanoparticles were formed due to these biocompatible polymers as the matrix in the nanocomposite. The study of Phan et al. [51] was the first to use CS as a directing-growth agent. However, this procedure synthesized gold nanourchins with a large core and short tip. Besides, ascorbic acid (AA), also known as vitamin $\mathrm{C}$, occurs in many natural foods and has wide applications in foods, cosmetics, and pharmaceuticals $[52,53]$, playing a role as a reducing agent. The evaluation of various conditions including $\mathrm{pH}$, concentration of $\mathrm{CS}$, and $\mathrm{AA}$ was performed to determine their influences on the morphology of GNS. Furthermore, the antibacterial activity of GNS against $P$. acnes was investigated by the well diffusion and plate count method. The antibacterial mechanism was observed using a scanning electron microscope (SEM). Furthermore, the mechanism that GNS killed bacteria was identified by SEM observation using simple preparation without any fixative and dehydrating step.

\section{Materials and Methods}

2.1. Materials. Chloroauric acid $\left(\mathrm{HAuCl}_{4} \cdot \mathrm{H}_{2} \mathrm{O}, 52 \%\right)$, chitosan (deacetylated chitin, low molecular weight), and acetic acid (glacial, 99\%) were obtained from Sigma-Aldrich. Ascorbic acid was purchased from Prolabo Company. 


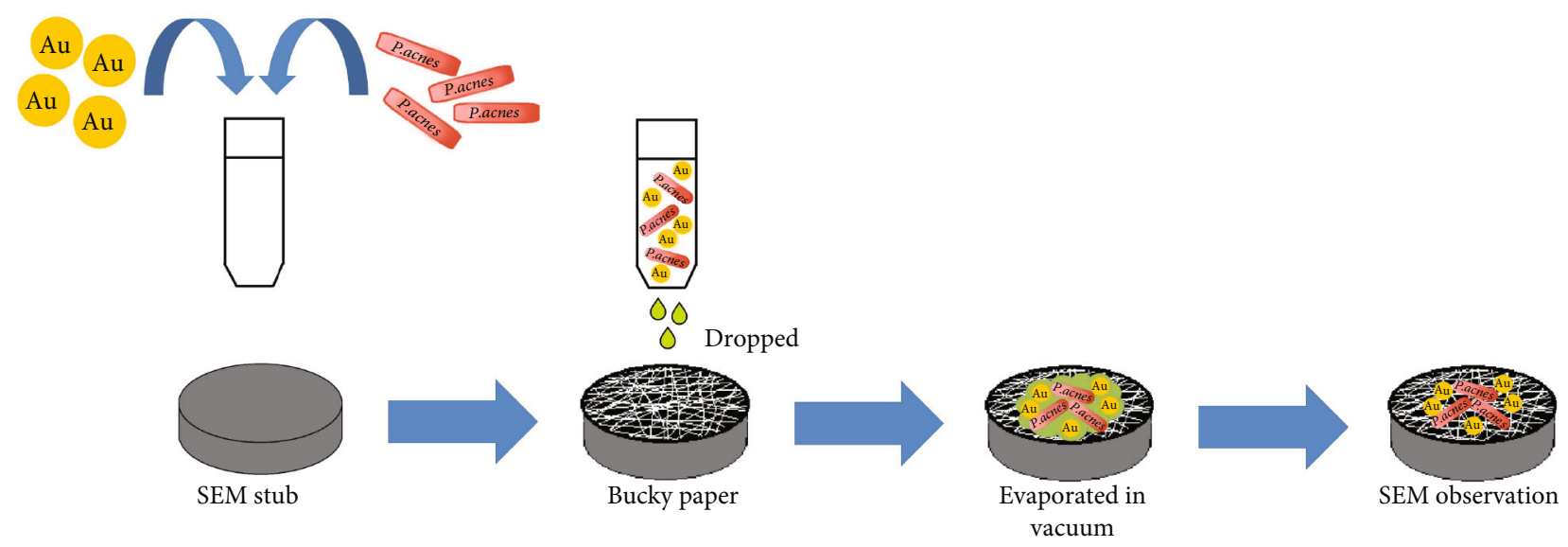

FIGURE 1: The procedure of sample preparation for observing bacterial specimen.

Deionized water $(18 \mathrm{M} \Omega$ ) was used throughout experiments. All chemical materials were of GR grade.

Propionibacterium acnes ATCC 11827 was ordered from Kwik-Stik. Tryptic Soy Agar (TSA) and thioglycollate broth were purchased from HiMedia. Ampicillin was obtained from Sigma-Aldrich.

2.2. One-Pot Preparation of Gold Nanostars. Firstly, CS $2 \%$ solution in acetic acid 1\% was made from low molecular weight CS powder and acetic acid. Next, $1 \mathrm{~mL}$ of $\mathrm{HAuCl}_{4} 2 \times 10^{-2} \mathrm{M}$ solution was added to $9 \mathrm{~mL}$ CS $2 \%$ solution under stirring. Acetic acid was used to adjust $\mathrm{pH}$. Finally, ascorbic acid (AA) $0.1 \mathrm{M}$ was dropped immediately into the mixture. The solution above was kept at least $30 \mathrm{~min}$ at room temperature. The color of the solution changed from colorless to cobalt blue indicating star-shaped particles formed. The influences of conditions including $\mathrm{pH}$, concentration of $\mathrm{CS}$, and AA on the morphology of GNS were studied.

2.3. Characterization of Gold Nanostars. A Jasco V-670 spectrophotometer was used to characterize the surface plasmon resonance (SPR) of GNS in the wavelength range of 400$900 \mathrm{~nm}$ and scanning rate of $200 \mathrm{~nm} / \mathrm{min}$. Interaction between GNS and CS was determined by Bruker Tensor 27 Fourier Transfer Infrared Spectroscopy (FTIR). All FTIR results were obtained from powder samples and did not apply smoothed or correction baseline. The crystal structure of GNS was determined employing X-ray diffraction (XRD). The scanning was carried out in the 2 theta range of $20^{\circ}-100^{\circ}$ using X-ray diffractometer Bruker D5005. Transmission electron microscope (TEM) analysis was examined by using JEM1010-JEOL. The average sizes of the core and branches were calculated by using ImageJ software (NHI Image) based on thirty particles of each sample. The GNS solutions were sonicated before measuring and examining.

\subsection{Evaluation of Antibacterial Effects against P. acnes}

2.4.1. Well Diffusion Method. The antibacterial activity of CScapped GNS was investigated using the agar well diffusion assay according to Qais et al. [54]. The organisms were grown in thioglycollate broth for 48 hours to obtain the colonyforming unit around $10^{8} \mathrm{CFU} / \mathrm{mL}$. Next, the bacterial inocu-

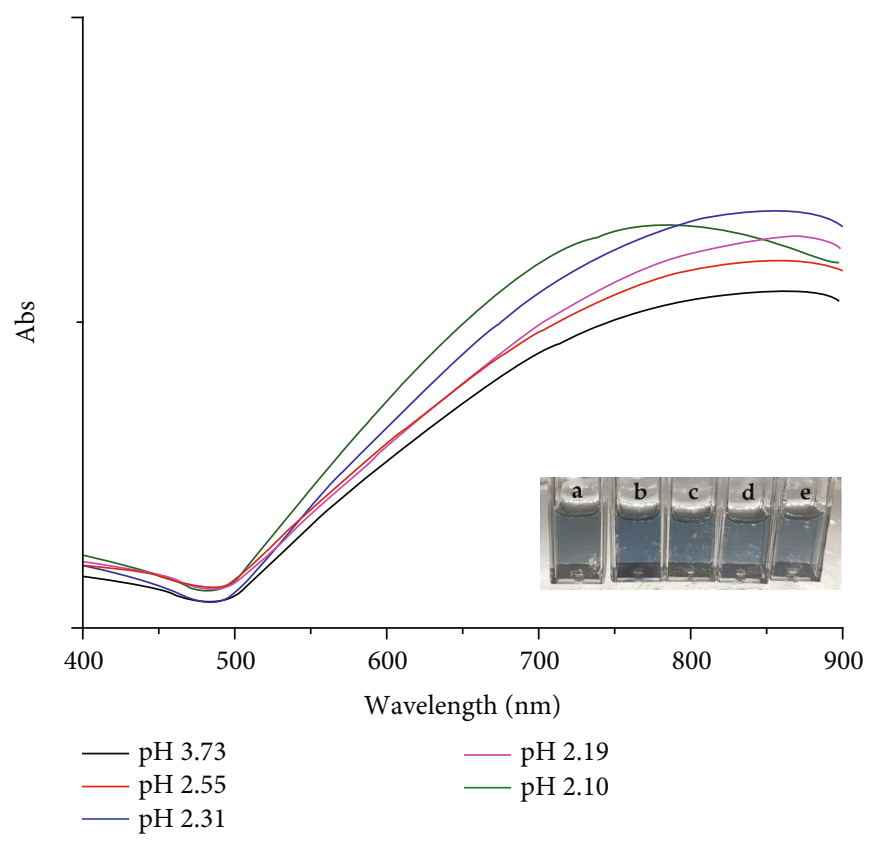

FIGURE 2: UV-Vis spectra of GNS prepared in various $\mathrm{pH}$.

lum was uniformly spread using a sterile cotton swab on sterile TSA plates. Wells of $6 \mathrm{~mm}$ diameter were punched by using sterilized micropipette tips. Different concentrations of CS-capped GNS (50,100, 150, and $200 \mu \mathrm{g} / \mathrm{mL})$ were poured into each well. All plates were incubated for $48 \mathrm{~h}$ at $37^{\circ} \mathrm{C}$, and diameters of the zone of inhibition were measured.

2.4.2. Plate Count Method. Viable bacterial cell concentrations were estimated by counting colony-forming units (CFU) with and without exposure to the CS-capped GNS on an agar plate [55]. The $P$. acnes bacteria were exposed to CS-capped GNS with different concentrations $(25,50,75$, and $100 \mu \mathrm{g} / \mathrm{mL}$ ). Ampicillin (Amp) $100 \mu \mathrm{g} / \mathrm{mL}$ was a positive control while DI water was a negative control. After $1 \mathrm{~min}$ ute, move $100 \mu \mathrm{L}$ of the solution above into a plate and pour Tryptic Soy Agar (TSA) to a plate. All plates were then incubated at $37^{\circ} \mathrm{C}$ for 72 hours, and CFU were counted. 


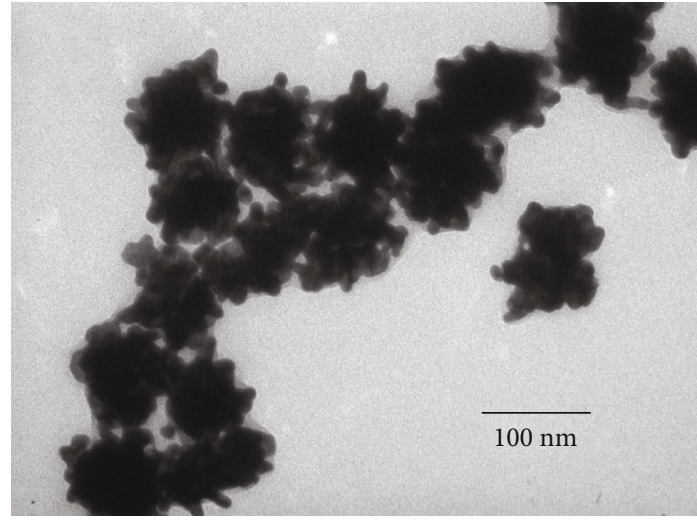

(a)



(b)

Figure 3: TEM images of GNS prepared in various $\mathrm{pH}$ : (a) $\mathrm{pH} 2.31$; (b) $\mathrm{pH} 2.10$.

2.4.3. Scanning Electron Microscope (SEM) Analysis. For the first time, a facile method was developed using a scanning electron microscope to observe the mechanism of GNS in destroying $P$. acnes. The procedure for the preparation of observing specimen is presented in Figure 1. To evaluate how GNS damaged the bacterium, we observed the uptake of gold nanoparticles into the bacterial membrane. After exposing gold colloidal solutions to $P$. acnes cultures, this mixture was directly dropped on stubs and evaporated in vacuum at $40^{\circ} \mathrm{C}$ without any fixative and dehydrating process. The SEM observation was carried out on Hitachi S4800 equipment at accelerating voltage $3 \mathrm{kV}$.

\section{Results and Discussion}

\subsection{The Influences of Reacting Conditions on the Morphology of GNS}

3.1.1. Influence of $p H$. Surface resonance plasmon (SPR) of GNS consists of two absorption bands ranging from 500 to $900 \mathrm{~nm}$, including a weaker peak at 500-575 $\mathrm{nm}$ referring to the core and an intense band in the NIR region $\left(\mathrm{SPR}_{\max }\right)$ ranging from 600 to $1200 \mathrm{~nm}$ referring to the branches of GNS [56]. Figure 2 shows the UV-Vis spectra of GNS prepared in various $\mathrm{pH}$ conditions. It was clear that the intensity of $\mathrm{SPR}_{\max }$ increased according to the decreasing $\mathrm{pH}$ from 3.73 while absorption locations were almost stable at $871 \mathrm{~nm}$. However, both intensity and $\mathrm{SPR}_{\max }$ declined when keeping on adjusting $\mathrm{pH}$ to 2.10. TEM images of GNS pre-

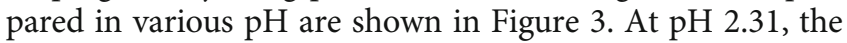
average size of the core and branches obtained $137.0 \pm 20.7$ $\mathrm{nm}$ and $33.5 \pm 9.7 \mathrm{~nm}$, respectively. The average size of the core expanded to $179.2 \pm 43.9 \mathrm{~nm}$ while branches decreased down to $14.0 \pm 4.4 \mathrm{~nm}$. It can be explained based on the effect of $\mathrm{pH}$ on oxidation/reduction of AA. Electrons produced by the oxidation process of $\mathrm{AA}$ reduced $\mathrm{Au}^{3+}$ to $\mathrm{Au}^{0}$. The oxidation rate of $\mathrm{AA}$ depended on $\mathrm{pH}$, faster toward basic $\mathrm{pH}$ but slower toward acidic $\mathrm{pH}$ [57]. Many electrons promoted due to the fast oxidation rate of $\mathrm{AA}$ at $\mathrm{pH} 3.73$ led to uncontrolled reducing reaction of $\mathrm{Au}^{3+}$ ions to $\mathrm{Au}^{0}$. By contrast, less electrons produced at $\mathrm{pH} 2.10$ were not enough to reduce all $\mathrm{Au}^{3+}$ ions to $\mathrm{Au}^{0}$. Moreover, $\mathrm{pH}$ affected the interaction of

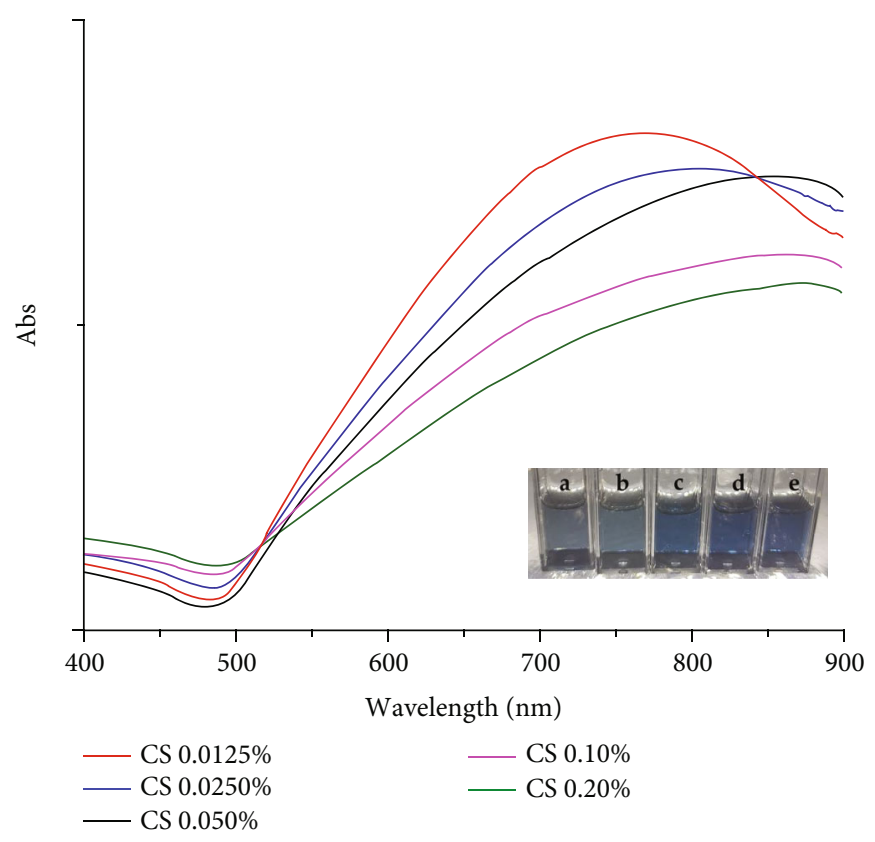

FIgURE 4: UV-Vis spectra of GNS prepared in various CS concentrations: (a) $0.0125 \%$; (b) $0.025 \%$; (c) $0.05 \%$; (d) $0.1 \%$; (e) $0.2 \%$.

CS and gold nanoparticles. CS was a directing-growth agent to assist star-shaped particle reaction. Value $\mathrm{pH}$ was driven to acidic condition which led to better dispersion of CS and interaction of $\mathrm{N}$-acetyl groups $\mathrm{NH}_{3}{ }^{+}$onto the surface of gold nanoparticles. But too many $\mathrm{N}$-acetyl groups $\mathrm{NH}_{3}{ }^{+}$attached onto nanoparticles' surface which led to steric hindrance, resulting in the decrease in the star-shaped yield.

3.1.2. Influence of CS Concentration. The absorption spectra of GNS synthesized in a variety of CS concentrations are shown in Figure 4. By increasing CS concentration from $0.0 .125 \%$ to $0.050 \%$, the $\mathrm{SPR}_{\max }$ shifted toward the NIR region, from $766 \mathrm{~nm}$ to $866 \mathrm{~nm}$. However, the $S_{P R}$ max almost were steady in spite of increasing CS concentration to $0.2 \%$. Moreover, the intensity of the $\mathrm{SPR}_{\max }$ peak declined corresponding to the CS increase in concentration. Figure 5 shows the morphology and size of synthesized gold nanostars in 


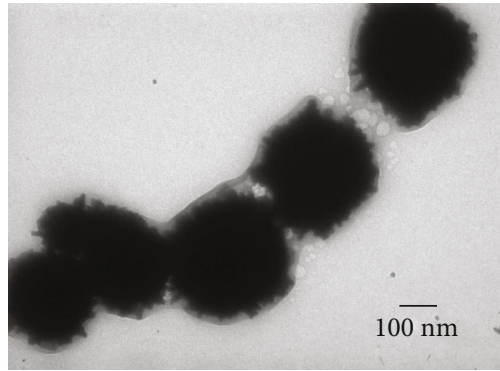

(a)

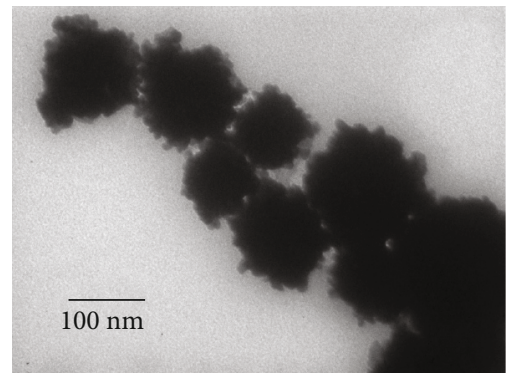

(b)

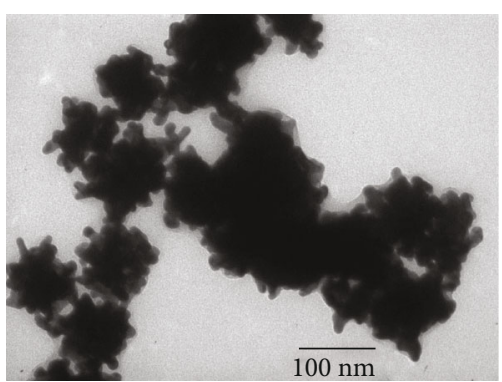

(c)

Figure 5: TEM images of GNS prepared in CS concentrations: (a) CS 0.0125\%; (b) CS 0.025\%; (c) CS 0.05\%.

different mass concentrations. CS mass concentration ranges from $0.0125 \%$ to $0.025 \%$, and there was a slight decline in the core from $281.9 \pm 25.8 \mathrm{~nm}$ to $216.5 \pm 33.2 \mathrm{~nm}$ whereas branches were elongated from $20.4 \pm 5.4 \mathrm{~nm}$ to $27.8 \pm 6.0$ $\mathrm{nm}$. The branches continuously prolonged to $54.2 \pm 11.9$ $\mathrm{nm}$ in spite of increasing CS mass concentration to $0.05 \%$. As discussed above, the role of CS was to direct growth to prepare star-shaped gold nanoparticles.

3.1.3. Influence of $A A$ Concentration. The effect of AA on plasmon surface resonance and morphology of GNS was exhibited by absorption spectra (Figure 6) and TEM analysis (Figure 7). Although the $\mathrm{SPR}_{\max }$ was steady at $875 \mathrm{~nm}$ when increasing AA concentration from $12.5 \times 10^{-4} \mathrm{M}$ to $25 \times$ $10^{-4} \mathrm{M}$, there was a significant increase in intensity of $\mathrm{SPR}_{\max }$. It was noticeable that $\mathrm{SPR}_{\max }$ shifted down to $741 \mathrm{~nm}$ and $658 \mathrm{~nm}$ despite increasing AA concentration to $50 \times 10^{-4} \mathrm{M}$ and $20 \times 10^{-3} \mathrm{M}$. The prepared GNS at AA 25 $\times 10^{-4} \mathrm{M}$ obtained $157.8 \pm 13.6 \mathrm{~nm}$ of the average core and $42.0 \pm 9.2 \mathrm{~nm}$ of the branched length. Meanwhile, the average length of branches was shorter and the average core was expanded, which resulted in $14.7 \pm 4.1 \mathrm{~nm}$ and $195.3 \pm$ $28.9 \mathrm{~nm}$, respectively. The reduction of $\mathrm{Au}^{3+}$ ions to $\mathrm{Au}^{0}$ due to electrons promoted the oxidation process of AA. The higher the AA concentration was, the more electrons were produced. At optimal AA concentration, the reduction to form GNS reacted gradually, which resulted in the high yield of star-shaped gold nanoparticles. By contrast, many electrons were promoted because of too high AA concentration which led to uncontrolled reduction.

3.2. Investigation of GNS-CS Interaction. Figure 8 shows the FTIR spectra of pure CS and CS-capped GNS. In the spectrum of pure CS, it was clear that a band located at around $2886 \mathrm{~cm}^{-1}$ corresponds to $\mathrm{C}-\mathrm{H}$ group stretching vibration [58]. Besides, there were two peaks at $1647 \mathrm{~cm}^{-1}$ and $1333 \mathrm{~cm}^{-1}$ relating to $\mathrm{C}=\mathrm{O}$ stretching vibration (amide $\mathrm{I}$ ) and C-N stretching (amide III), respectively [59]. Another band appeared at $1591 \mathrm{~cm}^{-1}$ corresponding to the bending vibration of N-H groups (amide II). These bands above confirmed the $\mathrm{N}$-acetyl groups of pure CS powder [60].

Compared with pure CS, the shift of bands was observed in the FTIR spectrum of CS-capped GNS. The C-H stretching shifted down to $2883 \mathrm{~cm}^{-1}$ while the bending of $\mathrm{N}-\mathrm{H}$ bonds disappeared. The $\mathrm{C}=\mathrm{O}$ groups of amide $\mathrm{I}$ and $\mathrm{C}-\mathrm{N}$ groups of amide III stretching vibration were located at

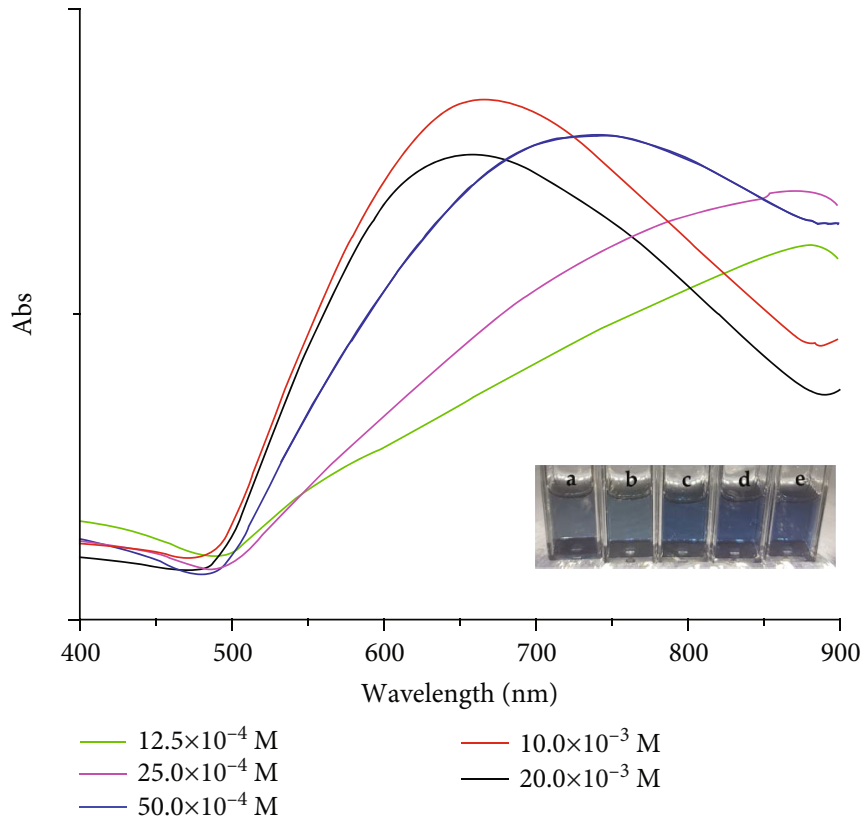

FIgURE 6: UV-Vis spectra of GNS prepared in various CS concentrations.

$1642 \mathrm{~cm}^{-1}$ and $1328 \mathrm{~cm}^{-1}$, respectively. These shifts indicated the interaction between functional groups of CS and GNS [61].

3.3. XRD of GNS. The recorded XRD pattern of GNS (Figure 9) exhibits four diffraction peaks that corresponded to (111), (200), (220), and (311) planes of gold with facecentered-cubic (fcc) structural crystal, respectively (ICDD PDF card number 00-004-0784) [62, 63]. An intense peak was located at $38.2^{\circ}$ that was indexed to the (111) plane. A moderate peak for the (220) plane was observed at $44.9^{\circ}$, and another appeared at $65.4^{\circ}$ for the (220) plane. Finally, there was a very weak peak at $77.7^{\circ}$ corresponding to the (311) plane.

\subsection{Evaluation of Antibacterial Effects against P. acnes}

3.4.1. Well Diffusion Method. Star-shaped gold nanoparticles synthesized in optimal conditions ( $\mathrm{pH} 2.31$, CS $0.05 \%$ and AA $25 \times 10^{-4} \mathrm{M}$ ) were used in antibacterial tests. The antibacterial activity against $P$. acnes of GNS using the well diffusion method is shown in Table 2. The results (Figure 10) 


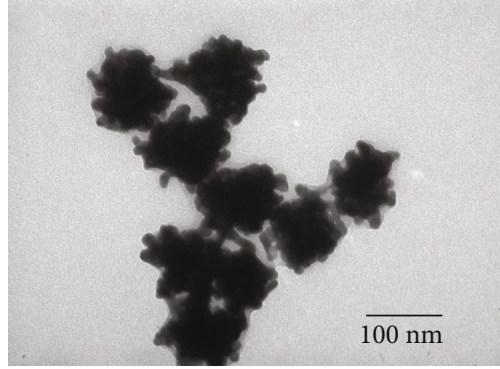

(a)

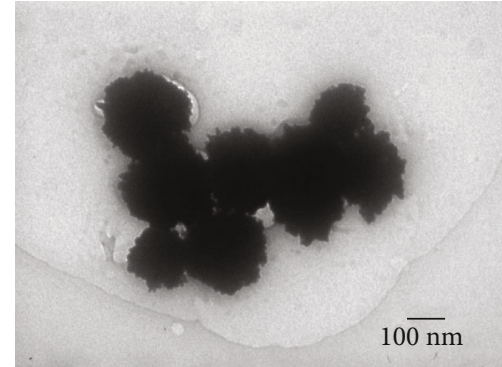

(b)

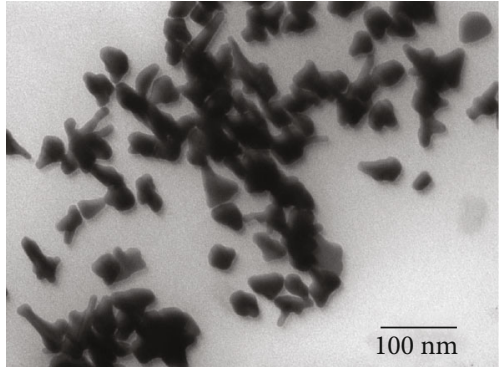

(c)

Figure 7: TEM images of NBPs prepared in various AA concentrations: (a) $25 \times 10^{-4} \mathrm{M}$; (b) $50 \times 10^{-4} \mathrm{M}$; (c) $20 \times 10^{-3} \mathrm{M}$.

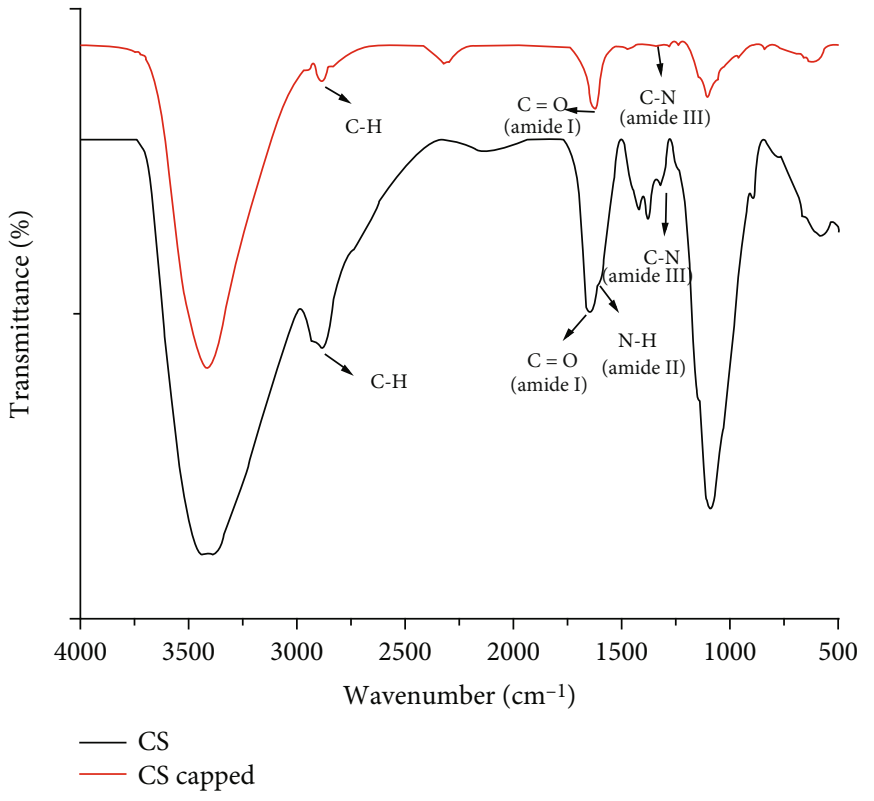

FIGURE 8: FTIR spectra of CS and CS-capped GNS.

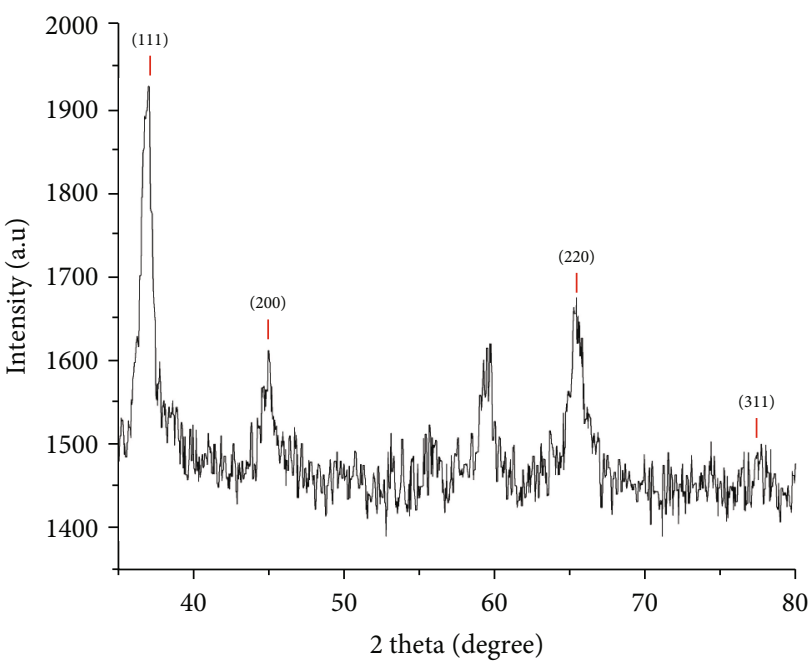

FIGURE 9: XRD patterns of GNS.

showed that GNS began to inhibit $P$. acnes at $100 \mu \mathrm{g} / \mathrm{mL}$. The zone of inhibitions was wider in spite of increasing GNS concentration. Therefore, the lowest concentration exhibiting
TABLE 2: Zone of inhibition of GNS against $P$. acnes in various concentrations.

\begin{tabular}{lcc}
\hline Samples & Concentration $(\mu \mathrm{g} / \mathrm{mL})$ & Zone of inhibition $(\mathrm{mm})$ \\
\hline $\mathrm{H}_{2} \mathrm{O}$ & - & - \\
GNS & 50 & - \\
GNS & 100 & $10.7 \pm 0.6$ \\
GNS & 150 & $12.7 \pm 1.2$ \\
GNS & 200 & $14.3 \pm 0.6$ \\
\hline
\end{tabular}

Zone of inhibition was measured as millimeter \pm standard deviation of at least three independent experiments. —: no activity.

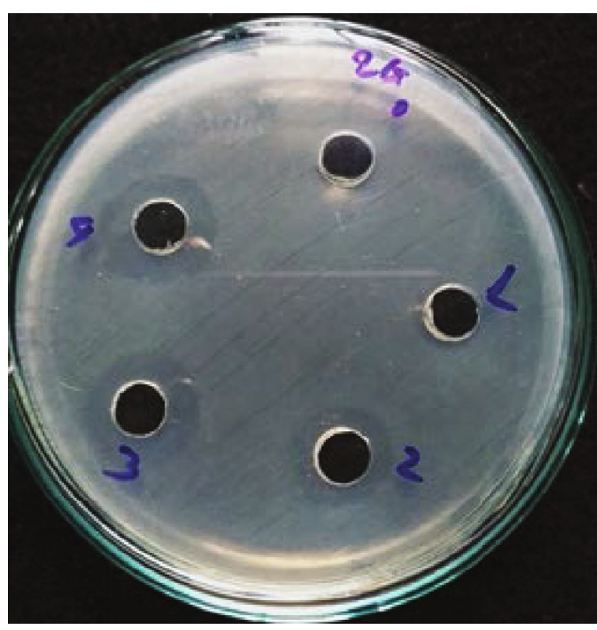

FIgURE 10: Antibacterial effect at various concentrations of GNS by the well diffusion method: (0) control $\left(\mathrm{H}_{2} \mathrm{O}\right),(1) 50 \mu \mathrm{g} / \mathrm{mL},(2)$ $100 \mu \mathrm{g} / \mathrm{mL}$, (3) $150 \mu \mathrm{g} / \mathrm{mL}$, and (4) $200 \mu \mathrm{g} / \mathrm{mL}$.

antibacterial activity was chosen as an end point in the plate count method.

3.4.2. Plate Count Method. Figure 11 shows the antibacterial effect of GNS against $P$. acnes in various concentrations ranging from $25 \mu \mathrm{g} / \mathrm{mL}$ to $100 \mu \mathrm{g} / \mathrm{mL}$ with Di water as a negative control and amp $100 \mu \mathrm{g} / \mathrm{mL}$ as a positive control. The antibacterial efficiency was calculated as follows:

$$
\text { Antibacterial efficiency }(\%)=\frac{\left(N_{\text {control }}-N_{\text {sample }}\right)}{N_{\text {control }}} \times 100
$$




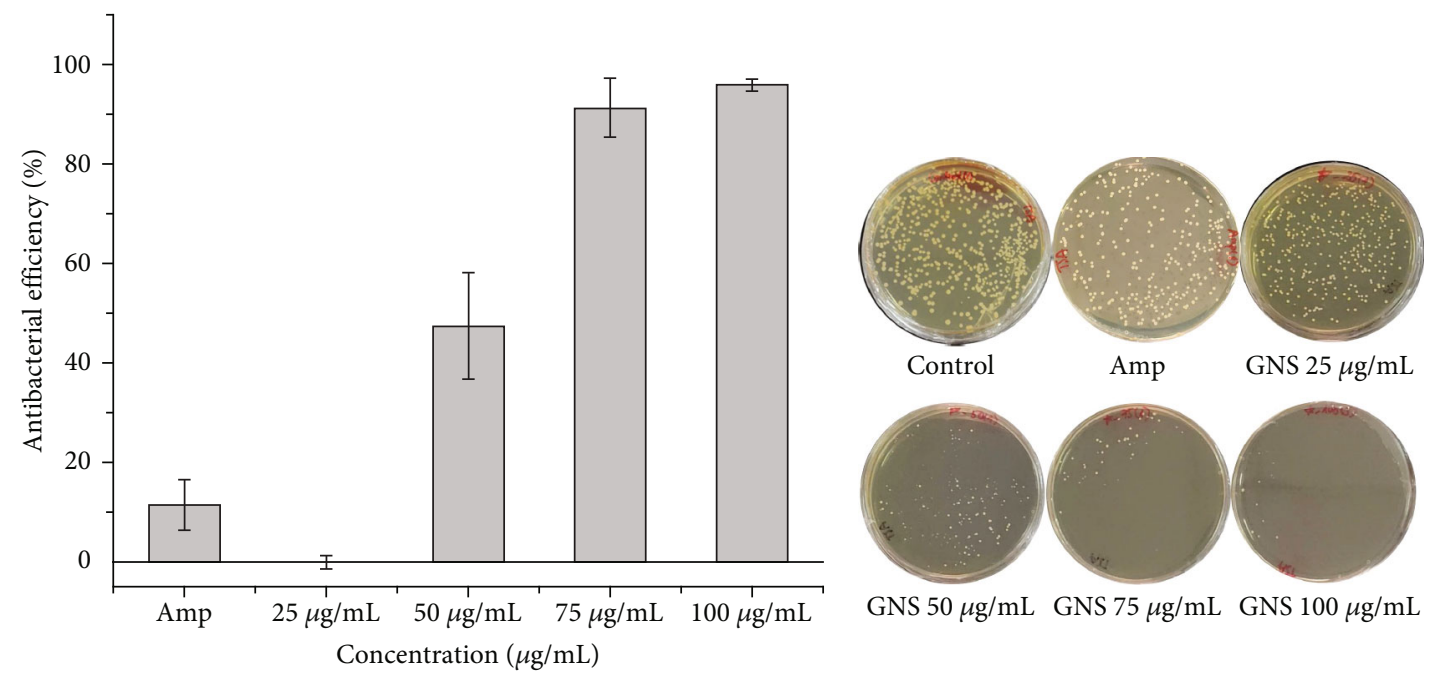

FIGURE 11: Antibacterial effect at various concentrations of GNS by the plate count method. Ampicillin $100 \mu \mathrm{g} / \mathrm{mL}$ was used as a positive control.
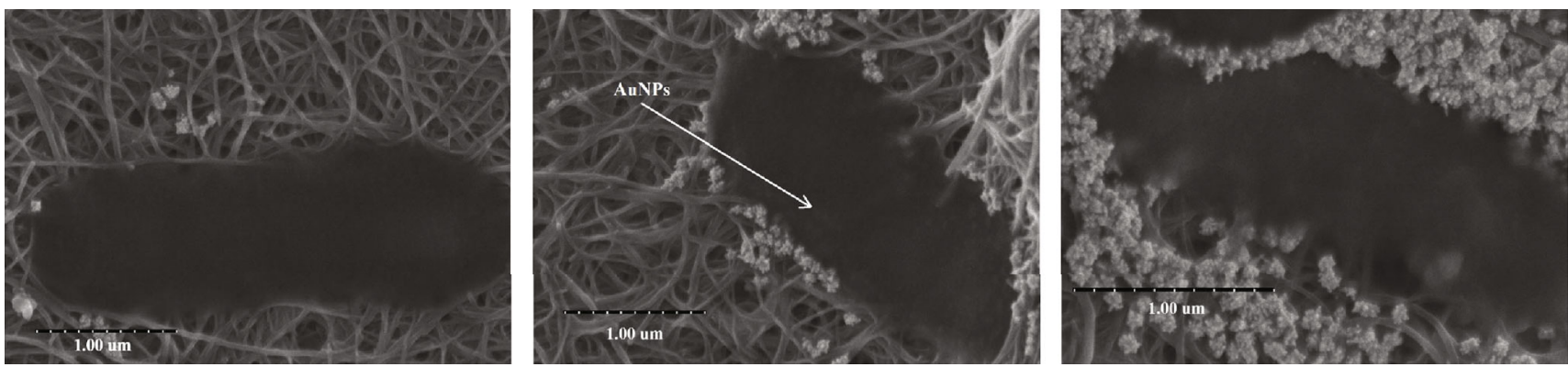

FIGURE 12: SEM micrographs of $P$. acnes before and after exposure to GNS.

where $N_{\text {control }}$ was the colonies counted in the negative control plate and $N_{\text {sample }}$ was the colonies counted in the sample plate exposed to GNS. It was noticeable that the antibacterial efficiency of amp $100 \mu \mathrm{g} / \mathrm{mL}$ was over $10 \%$. At $25 \mu \mathrm{g} / \mathrm{mL}$, there was no antibacterial activity against $P$. acnes of GNS. However, the antibacterial efficiency increased to around $45 \%$ at GNS $50 \mu \mathrm{g} / \mathrm{mL}$ concentration. The efficiency obtained more than $90 \%$ despite increasing GNS concentration to $75 \mu \mathrm{g} / \mathrm{mL}$, and $95 \%$ of $P$. acnes bacteria exposed to $100 \mu \mathrm{g} / \mathrm{mL}$ GNS were killed. It was noticeable that the antibacterial efficacy of amp $100 \mu \mathrm{g} / \mathrm{mL}$ was just over $10 \%$. According to the result, GNS exhibited significant antibacterial activity against $P$. acnes compared to ampicillin at the same concentration.

3.4.3. Scanning Electron Microscope (SEM) Analysis. Figure 12 shows SEM micrographs of $P$. acnes before and after exposure to GNS. It was clear that bacterial cells were damaged by GNS. The normal cell membranes of $P$. acnes bacteria before exposure to GNS were still stable and clear. However, after exposure to star-shaped gold particles, the cell membranes were deformed and appeared to have an amount of gold nanoparticles (AuNPs) inside bacterial cells. According to many studies before, there are three main mechanisms to kill bacteria of metallic nanoparticles including reactive oxidative species (ROS), releasing ion, and interaction of nanoparticles with the cell membrane [64]. Because gold nanoparticles (AuNPs) have no ROS and ion release [65], the interaction of AuNPs with the cell membrane is the only way to kill bacteria. The antibacterial activity of AuNPs depends on facets which are determined by the shape of nanoparticles. The spherical nanoparticles mainly have $\{100\}$ facets while the essential facets of starshaped nanoparticles are $\{111\}$. The facets $\{111\}$ have high antibacterial reactivity than $\{100\}[66,67]$. Therefore, spherical gold nanoparticles almost do not have an antibacterial effect. In contrast to this, GNS have good activity because of their primary facets $\{111\}$ in the crystalline structure. This can be demonstrated in XRD patterns of GNS in Figure 9. The mechanism to damage bacterium could be explained according to many earlier reported studies [68-70]; gold nanoparticles can interact with bacterial membranes and destroy them, leading to deformation or breaking of the cell membranes, which resulted in the leakage of bacterial components outside [71]. After that, they penetrate into the cytoplasm where they can inhibit the protein process. All of the mechanisms lead to bacterial death. 


\section{Conclusions}

In this study, we successfully synthesized GNS using a rapid and green method using safe materials such as ascorbic acid and chitosan. The prepared GNS were characterized using spectroscopic methods combining TEM and XRD to determine the optimal conditions. The average size of starbranched particles was ranging from $14.0 \pm 4.4 \mathrm{~nm}$ to 54.2 $\pm 17.9 \mathrm{~nm}$ depending on conditions. Besides, GNS revealed the significant antibacterial effects against Propionibacterium acnes determined by the well diffusion and plate count method. Gold nanostars are a prospective agent for replacing antibiotics to solve antibacterial resistance in acne treatment.

\section{Data Availability}

The data used to support the findings of this study have been deposited in the Data Availability Statement_No 6650661 repository. All data include figures, raw spectroscopy data, and .txt files (https://doi.org/10.6084/m9.figshare.13222175.v2/).

\section{Conflicts of Interest}

The authors declare that they have no conflicts of interest.

\section{Acknowledgments}

This work was financially supported by the Saigon Hi-Tech Park (grand number 01/2020/HĐNVTX-KCNC-TTRD) and the project of the Department of Science and Technology of Ho Chi Minh (118/2019/HĐ-QPTKHCN).

\section{References}

[1] J. K. L. Tan and K. Bhate, "A global perspective on the epidemiology of acne," British Journal of Dermatology, vol. 172, Supplement 1, pp. 3-12, 2015.

[2] I. Anina Lambrechts, M. Nuno de Canha, and N. Lall, "Chapter 4 - exploiting medicinal plants as possible treatments for acne vulgaris," in Medicinal Plants for Holistic Health and Well-Being, N. Lall, Ed., pp. 117-143, Academic Press, 2018.

[3] D. D. Lynn, T. Umari, R. Dellavalle, and C. Dunnick, "The epidemiology of acne vulgaris in late adolescence," Adolescent Health, Medicine and Therapeutics, vol. 7, pp. 13-25, 2016.

[4] N. Skroza, E. Tolino, A. Mambrin et al., "Adult acne versus adolescent acne: a retrospective study of 1,167 patients," The Journal of Clinical and Aesthetic Dermatology, vol. 11, no. 1, pp. 21-25, 2018.

[5] U. Gieler, T. Gieler, and J. Kupfer, "Acne and quality of life impact and management," Journal of the European Academy of Dermatology and Venereology, vol. 29, pp. 12-14, 2015.

[6] D. Well, "Acne vulgaris: a review of causes and treatment options," The Nurse Practitioner, vol. 38, no. 10, pp. 22-31, 2013.

[7] A. Linfante, R. M. Allawh, and H. B. Allen, "The role of propionibacterium acnes biofilm in acne vulgaris," Journal of Clinical \& Experimental Dermatology Research, vol. 9, no. 1, 2017.

[8] S. Mollerup, J. Friis-Nielsen, L. Vinner et al., "Propionibacterium acnes: Disease-causing agent or common contaminant? Detection in diverse patient samples by next-generation sequencing," Journal of Clinical Microbiology, vol. 54, no. 4, pp. 980-987, 2016.

[9] A. McDowell, S. Patrick, Y. Eishi, P. Lambert, and A. Eady, "Propionibacterium acnes in human health and disease," BioMed Research International, vol. 2013, Article ID 493564, 3 pages, 2013.

[10] M. A. T. Blaskovich, A. G. Elliott, A. M. Kavanagh, S. Ramu, and M. A. Cooper, "In vitro Antimicrobial Activity of Acne Drugs Against Skin-Associated Bacteria," Scientific Reports, vol. 9, no. 1, article 14658, 2019.

[11] Z. Yang, Y. Zhang, E. Lazic Mosler et al., “Topical benzoyl peroxide for acne," Cochrane Database of Systematic Reviews, vol. 3, no. 3, p. 579, 2020.

[12] J.-A. See, C. L. Goh, N. Hayashi, D. H. Suh, and F. A. Casintahan, "Optimizing the use of topical retinoids in Asian acne patients," The Journal of Dermatology, vol. 45, no. 5, pp. 522-528, 2018.

[13] T. Arif, "Salicylic acid as a peeling agent: a comprehensive review," Clinical, Cosmetic and Investigational Dermatology, vol. 8, pp. 455-461, 2015.

[14] K. Nakase, H. Nakaminami, Y. Takenaka, N. Hayashi, M. Kawashima, and N. Noguchi, "Relationship between the severity of acne vulgaris and antimicrobial resistance of bacteria isolated from acne lesions in a hospital in Japan," Journal of Medical Microbiology, vol. 63, no. 5, pp. 721-728, 2014.

[15] D. E. Castillo, S. Nanda, and J. E. Keri, "Propionibacterium (Cutibacterium) acnes bacteriophage therapy in acne: current evidence and future perspectives," Dermatology and Therapy, vol. 9, no. 1, pp. 19-31, 2019.

[16] S. Verma, P. Utreja, and L. Kumar, "Nanotechnological carriers for treatment of acne," Recent Patents on Anti-Infective Drug Discovery, vol. 13, no. 2, pp. 105-126, 2018.

[17] J. R. Antonio, C. R. Antonio, I. L. S. Cardeal, J. M. A. Ballavenuto, and J. R. Oliveira, "Nanotechnology in dermatology," Anais Brasileiros de Dermatologia, vol. 89, no. 1, pp. 126136, 2014.

[18] I. DeAlba-Montero, J. Guajardo-Pacheco, E. Morales-Sánchez et al., "Antimicrobial properties of copper nanoparticles and amino acid chelated copper nanoparticles produced by using a soya extract," Bioinorganic Chemistry and Applications, vol. 2017, Article ID 1064918, 6 pages, 2017.

[19] A. P. V. Ferreyra Maillard, S. Gonçalves, N. C. Santos, B. A. López de Mishima, P. R. Dalmasso, and A. Hollmann, "Studies on interaction of green silver nanoparticles with whole bacteria by surface characterization techniques," Biochimica et Biophysica Acta (BBA) - Biomembranes, vol. 1861, no. 6, pp. 10861092, 2019.

[20] E. Morales-Avila, G. Ferro-Flores, B. E. Ocampo-García et al., "Antibacterial efficacy of gold and silver nanoparticles functionalized with the ubiquicidin (29-41) antimicrobial peptide," Journal of Nanomaterials, vol. 2017, 10 pages, 2017.

[21] A. Akbar, M. B. Sadiq, I. Ali et al., "Synthesis and antimicrobial activity of zinc oxide nanoparticles against foodborne pathogens Salmonella typhimurium and Staphylococcus aureus," Biocatalysis and Agricultural Biotechnology, vol. 17, pp. 3642, 2019.

[22] N.-Y. T. Nguyen, N. Grelling, C. L. Wetteland, R. Rosario, and H. Liu, "Antimicrobial activities and mechanisms of magnesium oxide nanoparticles (nMgO) against pathogenic bacteria, yeasts, and biofilms," Scientific Reports, vol. 8, no. 1, article 16260, 2018. 
[23] S. Rehman, S. M. Asiri, F. A. Khan et al., "Biocompatible tin oxide nanoparticles: synthesis, antibacterial, anticandidal and cytotoxic activities," ChemistrySelect, vol. 4, no. 14, pp. 40134017, 2019.

[24] F. Valentini, A. Calcaterra, V. Ruggiero et al., "Functionalized graphene derivatives: antibacterial properties and cytotoxicity," Journal of Nanomaterials, vol. 2019, Article ID 2752539, 14 pages, 2019.

[25] L. F. Espinosa-Cristóbal, C. Holguín-Meráz, E. A. ZaragozaContreras et al., "Antimicrobial and substantivity properties of silver nanoparticles against oral microbiomes clinically isolated from young and young-adult patients," Journal of Nanomaterials, vol. 2019, Article ID 3205971, 14 pages, 2019.

[26] M. Perde-Schrepler, A. Florea, I. Brie et al., "Size-dependent cytotoxicity and genotoxicity of silver nanoparticles in cochlear cells in vitro," Journal of Nanomaterials, vol. 2019, Article ID 6090259, 12 pages, 2019.

[27] H. Peng, X. Zhang, Y. Wei et al., "Cytotoxicity of silver nanoparticles in human embryonic stem cell-derived fibroblasts and an L-929 cell line," Journal of Nanomaterials, vol. 2012, Article ID 160145, 9 pages, 2012.

[28] G. Rajendran, T. Rajamuthuramalingam, D. Michael Immanuel Jesse, and K. Kathiravan, "Synthesis and characterization of biocompatible acetaminophen stabilized gold nanoparticles," Materials Research Express, vol. 6, no. 9, article 095043, 2019.

[29] C. Carnovale, G. Bryant, R. Shukla, and V. Bansal, "Identifying trends in gold nanoparticle toxicity and uptake: size, shape, capping ligand, and biological corona," ACS Omega, vol. 4, no. 1, pp. 242-256, 2019.

[30] Y. Zhang, T. P. Shareena Dasari, H. Deng, and H. Yu, "Antimicrobial activity of gold nanoparticles and ionic gold," Journal of Environmental Science and Health, Part C, vol. 33, no. 3, pp. 286-327, 2015.

[31] C. G. Khoury and T. Vo-Dinh, "Gold nanostars for surfaceenhanced Raman scattering: synthesis, characterization and optimization," The Journal of Physical Chemistry C, vol. 112, no. 48, pp. 18849-18859, 2008.

[32] A. L. Rusanov, N. G. Luzgina, and A. V. Lisitsa, "Sodium dodecyl sulfate cytotoxicity towards HaCaT keratinocytes: comparative analysis of methods for evaluation of cell viability," Bulletin of Experimental Biology and Medicine, vol. 163, no. 2, pp. 284-288, 2017.

[33] P. Pati, S. McGinnis, and P. J. Vikesland, "Life cycle assessment of "green" nanoparticle synthesis methods," Environmental Engineering Science, vol. 31, no. 7, pp. 410-420, 2014.

[34] K. Wongyai, P. Wintachai, R. Maungchang, and P. Rattanakit, "Exploration of the antimicrobial and catalytic properties of gold nanoparticles greenly synthesized by Cryptolepis buchanani Roem. and Schult extract," Journal of Nanomaterials, vol. 2020, Article ID 1320274, 11 pages, 2020.

[35] F. J. Osonga, A. Akgul, I. Yazgan et al., "Size and shapedependent antimicrobial activities of silver and gold nanoparticles: a model study as potential fungicides," Molecules, vol. 25 , no. 11, article 2682, 2020.

[36] S. Shikha, S. R. Chaudhuri, and M. S. Bhattacharyya, "Facile One Pot Greener Synthesis of Sophorolipid Capped Gold Nanoparticles and its Antimicrobial Activity having Special Efficacy Against Gram Negative Vibrio cholerae," Scientific Reports, vol. 10, no. 1, p. 1463, 2020.

[37] T.-T. Vo, T. T. N. Nguyen, T. T. T. Huynh et al., "Biosynthesis of silver and gold nanoparticles using aqueous extract from
Crinum latifolium leaf and their applications forward antibacterial effect and wastewater treatment," Journal of Nanomaterials, vol. 2019, Article ID 8385935, 14 pages, 2019.

[38] S.-H. Kuo, C.-S. Chien, C.-C. Wang, and C.-J. Shih, “Antibacterial Activity of BSA-Capped Gold Nanoclusters against Methicillin- Resistant Staphylococcus aureus (MRSA) and Vancomycin-Intermediate Staphylococcus aureus (VISA)," Journal of Nanomaterials, vol. 2019, Article ID 4101293, 7 pages, 2019.

[39] P. Anbu, S. C. B. Gopinath, and S. Jayanthi, "Synthesis of gold nanoparticles usingPlatycodon grandiflorumextract and its antipathogenic activity under optimal conditions," Nanomaterials and Nanotechnology, vol. 10, 2020.

[40] J. H. Clark, "Chapter 1: green and sustainable chemistry: an introduction," in Green and Sustainable Medicinal Chemistry: Methods, Tools and Strategies for the 21st Century Pharmaceutical Industry (Green Chemistry Series), p. 221, The Royal Society of Chemistry, 2016.

[41] H. Duan, D. Wang, and Y. Li, "Green chemistry for nanoparticle synthesis," Chemical Society Reviews, vol. 44, no. 16, pp. 5778-5792, 2015.

[42] G. Chatel and R. S. Varma, "Ultrasound and microwave irradiation: contributions of alternative physicochemical activation methods to green chemistry," Green Chemistry, vol. 21, no. 22, pp. 6043-6050, 2019.

[43] H. Yuan, C. G. Khoury, H. Hwang, C. M. Wilson, G. A. Grant, and T. Vo-Dinh, "Gold nanostars: surfactant-free synthesis, 3D modelling, and two-photon photoluminescence imaging," Nanotechnology, vol. 23, no. 7, article 075102, 2012.

[44] P.-Y. Shih, Y.-T. Liao, Y.-K. Tseng, F.-S. Deng, and C.-H. Lin, "A potential antifungal effect of chitosan against Candida albicans is mediated via the inhibition of SAGA complex component expression and the subsequent alteration of cell surface integrity," Frontiers in Microbiology, vol. 10, p. 602, 2019.

[45] P. Sahariah and M. Másson, "Antimicrobial chitosan and chitosan derivatives: a review of the structure-activity relationship," Biomacromolecules, vol. 18, no. 11, pp. 3846-3868, 2017.

[46] A. Barra, Z. Alves, N. M. Ferreira et al., "Biocompatible chitosan-based composites with properties suitable for hyperthermia therapy," Journal of Materials Chemistry B, vol. 8, no. 6, pp. 1256-1265, 2020.

[47] D. Bharathi, R. Ranjithkumar, B. Chandarshekar, and V. Bhuvaneshwari, "Bio-inspired synthesis of chitosan/copper oxide nanocomposite using rutin and their anti-proliferative activity in human lung cancer cells," International Journal of Biological Macromolecules, vol. 141, pp. 476-483, 2019.

[48] C. N. Nandana, M. Christeena, and D. Bharathi, "Synthesis and characterization of chitosan/silver nanocomposite using rutin for antibacterial, antioxidant and photocatalytic applications," Journal of Cluster Science, 2021.

[49] S. Preethi, K. Abarna, M. Nithyasri et al., "Synthesis and characterization of chitosan/zinc oxide nanocomposite for antibacterial activity onto cotton fabrics and dye degradation applications," International Journal of Biological Macromolecules, vol. 164, pp. 2779-2787, 2020.

[50] S. Tharani, D. Bharathi, and R. Ranjithkumar, "Extracellular green synthesis of chitosan-silver nanoparticles using Lactobacillus reuteri for antibacterial applications," Biocatalysis and Agricultural Biotechnology, vol. 30, article 101838, 2020.

[51] T. T. V. Phan, V. T. Nguyen, S.-H. Ahn, and J. Oh, "Chitosanmediated facile green synthesis of size-controllable gold 
nanostars for effective photothermal therapy and photoacoustic imaging," European Polymer Journal, vol. 118, pp. 492-501, 2019.

[52] J. Singh and A. Mirza, "Influence of ascorbic acid application on quality and storage life of fruits," International Journal of Current Microbiology and Applied Sciences, vol. 7, no. 7, pp. 4319-4328, 2018.

[53] S. Ravetti, Clemente, Brignone, Hergert, Allemandi, and Palma, "Ascorbic acid in skin health," Cosmetics, vol. 6, no. 4 , p. $58,2019$.

[54] F. A. Qais, A. Shafiq, H. M. Khan et al., “Antibacterial effect of silver nanoparticles synthesized using Murraya koenigii (L.) against multidrug-resistant pathogens," Bioinorganic Chemistry and Applications, vol. 2019, Article ID 4649506, 11 pages, 2019.

[55] C. Bankier, Y. Cheong, S. Mahalingam et al., "A comparison of methods to assess the antimicrobial activity of nanoparticle combinations on bacterial cells," PLoS One, vol. 13, no. 2, article e0192093, 2018.

[56] N.-Y. Lee, W.-C. Ko, and P.-R. Hsueh, "Nanoparticles in the treatment of infections caused by multidrug-resistant organisms," Frontiers in Pharmacology, vol. 10, pp. 1153-1153, 2019.

[57] T. Moura, D. Gaudy, M. Jacob, and G. Cassanas, "pH influence on the stability of ascorbic acid spray-drying solutions," Pharmaceutica Acta Helvetiae, vol. 69, no. 2, pp. 77-80, 1994.

[58] H. R. de Barros, L. Piovan, G. L. Sassaki et al., "Surface interactions of gold nanorods and polysaccharides: from clusters to individual nanoparticles," Carbohydrate Polymers, vol. 152, pp. 479-486, 2016.

[59] C. O. Mohan, S. Gunasekaran, and C. N. Ravishankar, "Chitosan-capped gold nanoparticles for indicating temperature abuse in frozen stored products," Npj Science of Food, vol. 3, no. 1, p. 2, 2019.

[60] M. Fernandes Queiroz, K. Melo, D. Sabry, G. Sassaki, and H. Rocha, "Does the use of chitosan contribute to oxalate kidney stone formation?," Marine Drugs, vol. 13, no. 1, pp. 141158, 2015.

[61] P. Abrica-González, J. A. Zamora-Justo, A. Sotelo-López et al., "Gold nanoparticles with chitosan, N-acylated chitosan, and chitosan oligosaccharide as DNA carriers," Nanoscale Research Letters, vol. 14, no. 1, pp. 258-258, 2019.

[62] M. J. Oliveira, M. P. de Almeida, D. Nunes et al., "Design and simple assembly of gold nanostar bioconjugates for surfaceenhanced Raman spectroscopy immunoassays," Nanomaterials, vol. 9, no. 11, article 1561, 2019.

[63] V.-D. Doan, B. A. Huynh, T. D. Nguyen et al., "Biosynthesis of silver and gold nanoparticles using aqueous extract of Codonopsis pilosula roots for antibacterial and catalytic applications," Journal of Nanomaterials, vol. 2020, Article ID 8492016, 18 pages, 2020.

[64] S. Shamaila, N. Zafar, and R. Sharif, Antibacterial activity of metallic nanoparticles, p. 20, 2018.

[65] E. A. Ortiz-Benítez, N. Velázquez-Guadarrama, N. V. Durán Figueroa, H. Quezada, and J. . J. Olivares-Trejo, “Antibacterial mechanism of gold nanoparticles on Streptococcus pneumoniae," Metallomics, vol. 11, no. 7, pp. 1265-1276, 2019.

[66] A. Qidwai, A. Pandey, R. Kumar, S. K. Shukla, and A. Dikshit, "Advances in Biogenic Nanoparticles and the Mechanisms of antimicrobial Effects," Indian Journal of Pharmaceutical Sciences, vol. 80, no. 4, p. 11, 2018.
[67] Y. N. Slavin, J. Asnis, U. O. Häfeli, and H. Bach, "Metal nanoparticles: understanding the mechanisms behind antibacterial activity," Journal of Nanobiotechnology, vol. 15, no. 1, p. 65, 2017.

[68] P. V. Baptista, M. P. McCusker, A. Carvalho et al., "Nanostrategies to fight multidrug resistant bacteria- "a battle of the titans"," Frontiers in Microbiology, vol. 9, article 1441, 2018.

[69] C. Tao, "Antimicrobial activity and toxicity of gold nanoparticles: research progress, challenges and prospects," Letters in Applied Microbiology, vol. 67, no. 6, pp. 537-543, 2018.

[70] Y. Zhao and X. Jiang, "Multiple strategies to activate gold nanoparticles as antibiotics," Nanoscale, vol. 5, no. 18, pp. 8340-8350, 2013.

[71] D. P. Linklater, V. A. Baulin, X. le Guével et al., “Antibacterial action of nanoparticles by lethal stretching of bacterial cell membranes," Advanced Materials, vol. 32, no. 52, article 2005679, 2020. 